\title{
Ceramic Water Filters for the Removal of Bacterial, Chemical, and Viral Contaminants
}

\author{
Pierre-Marie Nigay ${ }^{1}$; Ali A. Salifu ${ }^{2}$; John D. Obayemi ${ }^{3}$; Claire E. White ${ }^{4}$; Ange Nzihou ${ }^{5}$; \\ and Winston O. Soboyejo ${ }^{6}$
}

\begin{abstract}
In this study, the combination of capture mechanisms in ceramic water filters (doped with hydroxyapatite and alumina) was considered for the removal of contaminants from drinking water. It was found that hydroxyapatite and alumina were conserved during the firing process of the ceramic water filters up to $950^{\circ} \mathrm{C}$. The nanopores resulting from the conservation of the additives increased the specific surface area of the ceramic water filters from 3.7 to $21.0 \mathrm{~m}^{2} \cdot \mathrm{g}^{-1}$. On the other hand, the microscopic pores associated with the processing of the ceramic water filters (i.e., pressing and drying) and the combustion of the sawdust reduced the filtration time from 24 to $4 \mathrm{~h}$. The efficiency of the resulting filters in removing bacterial, chemical, and viral contaminants from water was investigated using $E$. coli, fluoride, and MS2 as model contaminants. The contaminants were found to be captured from water by trapping in the pores, substitution in the hydroxyapatite, and adsorption on the surface of alumina. Hence, the ceramic water filters incorporating hydroxyapatite and alumina combined the different capture mechanisms. They had an efficiency of $99.998 \%, 99.970 \%$, and $99.450 \%$ in the removal of bacterial, chemical, and viral contaminants, corresponding to log reduction values (LRVs) of 4.69, 3.47, and 2.26, respectively.
\end{abstract}

Author keywords: Ceramic water filters; Bacteria; Chemicals; Viruses; Household water treatment.

\section{Introduction}

Ceramic water filters are regarded as the most efficient technology for household water treatment in developing countries (Sobsey et al. 2008). They can be used at home by people or communities that do not have access to safe drinking water. They also have the greatest potential among point-of-use technologies (e.g., boiling, chlorination, pasteurization, flocculation, solar disinfection, and biosand filtration) for widespread use due to their ease of production, ease of operation, and relatively high efficiency at removing bacterial contaminants from drinking water (Hunter 2009; Bielefeldt et al. 2009).

Typically, bacterial contaminants are trapped in the nano- and microscale pores of ceramic water filters when the water that has been introduced flows through their porous structure

${ }^{1}$ Postdoctoral Researcher, Dept. of Mechanical Engineering, Worcester Polytechnic Institute, Worcester, MA 01609 (corresponding author). ORCID: https://orcid.org/0000-0003-2204-6205. Email: pmnigay@mines -albi.fr

${ }^{2}$ Assistant Research Professor, Dept. of Biology and Biotechnology, Worcester Polytechnic Institute, Worcester, MA 01609. Email: aasalifu@ wpi.edu

${ }^{3}$ Assistant Research Professor, Dept. of Biology and Biotechnology, Worcester Polytechnic Institute, Worcester, MA 01609. Email: jdobayemi@ wpi.edu

${ }^{4}$ Assistant Professor, Dept. of Civil and Environmental Engineering and Andlinger Center for Energy and the Environment, Princeton Univ., Princeton, NJ 08544. Email: whitece@princeton.edu

${ }^{5}$ Professor, Centre RAPSODEE, Ecole des Mines d'Albi, Campus Jarlard, Route de Teillet, Albi Cedex 09 81013, France. Email: ange .nzihou@mines-albi.fr

${ }^{6}$ Provost, Dept. of Mechanical Engineering, Worcester Polytechnic Institute, Worcester, MA 01609. Email: wsoboyejo@wpi.edu
(Oyanedel-Craver and Smith 2008). Prior studies showed that ceramic water filters can remove more than $99.9 \%$ of bacterial contaminants (e.g., E. coli) from water (Yakub et al. 2013; van der Laan et al. 2014). This represents a significant step forward in improving the quality of drinking water, with infectious diarrhea caused by the presence of such contaminants in water being responsible for the loss of three million lives per year [World Health Organization (WHO 2001)]. Nevertheless, water can still be unsafe to drink due to the presence of chemical contaminants.

The presence of chemical contaminants (e.g., heavy metals, pesticides) can compromise the functioning of vital organs (Järup 2003; Younes and Galal-Gorchev 2000). An excess of certain elements, such as fluoride, may also result in skeletal deformities or dental problems (Meenakshi and Maheshwari 2006). This motivated several studies on the doping of ceramic water filters with hydroxyapatite. Chemical contaminants from drinking water are captured by hydroxyapatite in clay structures. It has been shown that hydroxyapatite captures chemical contaminants via a substitution mechanism (Bhatnagar et al. 2011). Typically, the capture mechanism of substitution resulted in a $93 \%$ removal of fluoride from drinking water (Yakub and Soboyejo 2013).

Drinking water is also the main vector of transmission of viruses in countries in the developing world (Ramia 1985). Viruses such as polio enter the body through the mouth from fecally contaminated water and cause paralysis of essential muscles (Racaniello 2006). To combat this issue, several techniques have been implemented. Most of them were based on the use of metal oxides. Typically, the metal oxides capture viruses from drinking water by adsorption (Michen et al. 2012, 2013). Some studies have shown that iron, aluminum, or magnesium oxides removed more than $99 \%$ of viral contaminants (Brown and Sobsey 2009, 2010). Recent studies have shown that such metal oxides can also be incorporated into ceramic water filters (Tsao et al. 2016).

Therefore, the objective of this study is to combine the capture mechanisms (i.e., trapping, substitution, and adsorption) in ceramic 
Table 1. Elemental composition of clay, hydroxyapatite, and alumina obtained using TXRF analysis

\begin{tabular}{|c|c|c|c|c|c|c|}
\hline \multirow[b]{2}{*}{ Sample } & \multicolumn{6}{|c|}{ Concentration (wt.\%) } \\
\hline & $\mathrm{SiO}_{2}$ & $\mathrm{Al}_{2} \mathrm{O}_{3}$ & $\mathrm{Fe}_{2} \mathrm{O}_{3}$ & $\mathrm{~K}_{2} \mathrm{O}$ & $\mathrm{CaO}$ & $\mathrm{P}_{2} \mathrm{O}_{5}$ \\
\hline Clay & $63.7 \pm 4.2$ & $15.2 \pm 1.2$ & $7.9 \pm 0.2$ & $4.1 \pm 0.3$ & $0.5 \pm 0.4$ & $0.3 \pm 0.0$ \\
\hline $\mathrm{HA}$ & $0.0 \pm 0.0$ & $0.0 \pm 0.0$ & $0.2 \pm 0.1$ & $0.3 \pm 0.1$ & $47.3 \pm 0.3$ & $41.4 \pm 0.0$ \\
\hline $\mathrm{AL}$ & $0.1 \pm 0.0$ & $98.7 \pm 0.4$ & $0.2 \pm 0.2$ & $0.1 \pm 0.0$ & $0.1 \pm 0.1$ & $0.0 \pm 0.0$ \\
\hline
\end{tabular}

Note: Error ranges of elemental composition were determined from standard deviation of three replicates. AL = alumina; and HA = hydroxyapatite.

water filters with hydroxyapatite and alumina for the removal of bacterial, chemical, and viral contaminants from drinking water. The impact of hydroxyapatite and alumina on the structure and hydraulic performances of ceramic water filters will be investigated. The efficiency of ceramic water filters at removing contaminants from drinking water will also be related to the structure and hydraulic performance. In this way, the removal of bacterial, chemical, and viral contaminants can be associated with the different capture mechanisms.

\section{Materials and Methods}

\section{Raw Materials}

The clay used in this study consisted of redart airfloated clay (Cedar Heights, Resco Products, Pittsburgh). The elemental composition was measured using total reflection X-ray fluorescence (TXRF) spectrometry (S2 PICOFOX, Bruker, Camarillo, California). The results of the TXRF analyses are given in Table 1. They show a predominance of silicon and aluminum oxides, with smaller concentrations of iron, potassium, calcium, and phosphorus oxides.

The additives used in this study consisted of sawdust (SD), hydroxyapatite (HA), and alumina (AL). The sawdust (oak and pine) was obtained from a local sawmill (JB Sawmill \& Landclearing, Hopkinton, Massachusetts). Prior to use, the sawdust was subjected to $500 \mu \mathrm{m}$ sieving. The elemental composition of the sawdust, measured via CHONS (Carbon, Hydrogen, Oxygen, Nitrogen, Sulfur) analysis (Flash 2000, Thermo Fisher Scientific, Waltham, Massachusetts), is given in Table 2. The results show that it is composed of carbon, oxygen, and hydrogen, with smaller concentrations of nitrogen. The hydroxyapatite consisted of a commercial product (TCP 108) obtained from Prayon (Engis, Belgium). It is composed of calcium and phosphorus oxides with residual oxides of iron and potassium (TXRF results in Table 1). Finally, the alumina (Brockmann I) was obtained from Sigma-Aldrich (St. Louis, Missouri). The results of the TXRF analysis show a predominance of aluminum oxide with trace levels of silicon, iron, potassium, and calcium oxides.

The particle size distribution of the additives was measured via laser granulometry analysis (Mastersizer 3000, Malvern Instruments, Malvern, UK). The results of the laser granulometry analysis are presented in Fig. 1, which shows an average particle size of $500 \mu \mathrm{m}$ for the sawdust, $5 \mu \mathrm{m}$ for the hydroxyapatite, and $100 \mu \mathrm{m}$ for the alumina.

Table 2. Elemental composition of sawdust obtained using CHONS analysis

\begin{tabular}{lccccc}
\hline & \multicolumn{5}{c}{ Concentration (wt.\%) } \\
\cline { 2 - 6 } Sample & C & H & O & N & S \\
\hline SD & $46.8 \pm 0.1$ & $5.9 \pm 0.1$ & $32.7 \pm 1.7$ & $0.2 \pm 0.0$ & $0.0 \pm 0.0$ \\
\hline
\end{tabular}

Note: Error ranges of elemental composition were determined from standard deviation of three replicates.

\section{Processing of Ceramic Water Filters}

The ceramic water filters investigated in this study were produced from different mixtures of clay, sawdust, hydroxyapatite, and alumina. The sawdust was used as a pore-forming agent to trap some contaminants in the pores while water flowed through the clay matrix. On the other hand, hydroxyapatite and alumina were used for their substitution and adsorption properties, respectively (see "Introduction").

The mixtures were prepared in a kneading ball. They were subjected to kneading with a gradual addition of water (up to the formation of pastes). The composition of the different mixtures is summarized in Table 3. It can be observed that the weight concentration of sawdust was set to $15 \mathrm{wt} . \%$, which consists in a volume

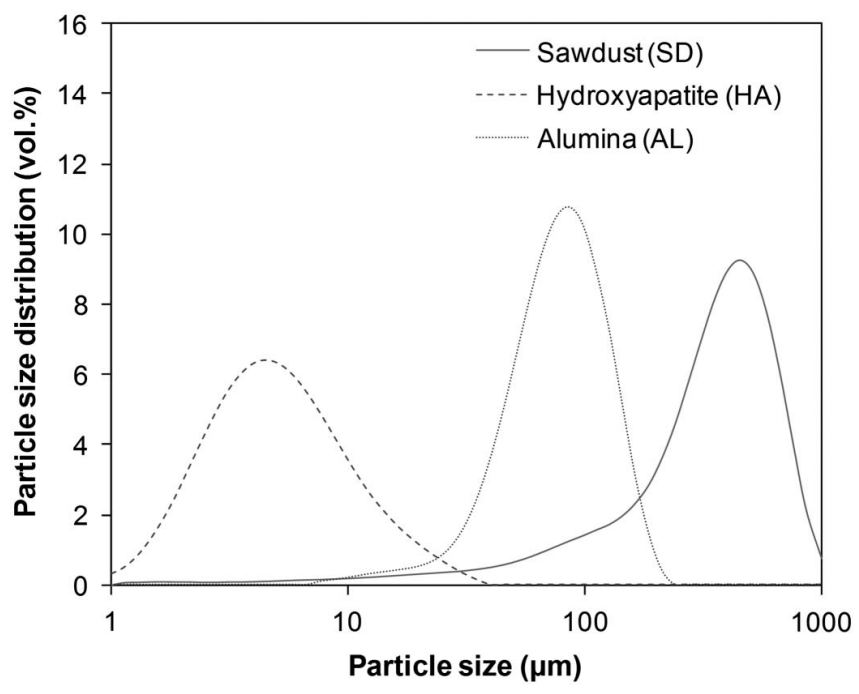

Fig. 1. Particle size distribution of sawdust (SD), hydroxyapatite (HA), and alumina (AL) obtained using laser granulometry analysis.

Table 3. Composition of the mixtures by weight and volume concentrations of clay, sawdust (SD), hydroxyapatite (HA), and alumina (AL) of the ceramic water filters

\begin{tabular}{|c|c|c|c|c|c|c|c|c|}
\hline \multirow[b]{2}{*}{ Sample } & \multicolumn{4}{|c|}{$\begin{array}{c}\text { Concentration } \\
\text { (wt.\%) }\end{array}$} & \multicolumn{4}{|c|}{$\begin{array}{c}\begin{array}{c}\text { Concentration } \\
(\text { vol. } \%)\end{array} \\
\end{array}$} \\
\hline & Clay & SD & HA & $\mathrm{AL}$ & Clay & SD & HA & $\mathrm{AL}$ \\
\hline CWF & 85 & 15 & 0 & 0 & 50 & 50 & 0 & 0 \\
\hline $\begin{array}{l}\mathrm{CWF}+20 \text { wt. } \% \\
\mathrm{HA}\end{array}$ & 65 & 15 & 20 & 0 & 40 & 50 & 10 & 0 \\
\hline $\begin{array}{l}\mathrm{CWF}+20 \text { wt. } \% \\
\mathrm{AL}\end{array}$ & 65 & 15 & 0 & 20 & 40 & 50 & 0 & 10 \\
\hline $\begin{array}{l}\text { CWF + } 40 \text { wt. } \% \\
\text { HA/AL }\end{array}$ & 45 & 15 & 20 & 20 & 30 & 50 & 10 & 10 \\
\hline
\end{tabular}


concentration of 50 vol. $\%$. On the other hand, the weight concentration of hydroxyapatite or alumina was set to 20 wt.\% (i.e., 10 vol.\%). These values were considered optimum (removal efficiency, mechanical properties) from the results of a previous study by the authors (Nigay et al. 2018).

The resulting pastes were pressed into frustum-shaped materials using a hydraulic press (TRD55002, Torin, Ontario, California) with a two-piece aluminum mold (base diameter of $210 \mathrm{~mm}$, lid diameter of $300 \mathrm{~mm}$, and height of $250 \mathrm{~mm}$ ). The frustum-shaped materials were obtained using a pressure of $20 \mathrm{t}$. Two were produced for each mixture with a thickness of approximately $15 \mathrm{~mm}$ for the base and $10 \mathrm{~mm}$ for the sides. After pressing, they were air dried at room temperature. The drying time varied between 5 and 8 days, depending on the amount of water that was used to produce the pastes. After drying, the frustum-shaped materials were subjected to firing in an electric kiln (Dragon24, Paragon, Mesquite, Texas). They were fired at a temperature of $950^{\circ} \mathrm{C}$ for $3 \mathrm{~h}$ at a heating rate of $50^{\circ} \mathrm{C} / \mathrm{h}$ from $30^{\circ} \mathrm{C}$ to $500^{\circ} \mathrm{C}$ and a heating rate of $100^{\circ} \mathrm{C} / \mathrm{h}$ from $500^{\circ} \mathrm{C}$ to $950^{\circ} \mathrm{C}$.

\section{Characterization of Ceramic Water Filters}

The thermal behavior of the ceramic water filters was determined via thermogravimetric analysis (TGA). The determination of the mass loss as a function of the temperature was obtained using a TG 209 F1 Libra apparatus (Netzsch, Selb, Germany). The analyses were performed using unfired samples with a mass of approximately $200 \mathrm{mg}$. The data were collected in an air atmosphere at temperatures between $30^{\circ} \mathrm{C}$ and $1,000^{\circ} \mathrm{C}$ at a $5^{\circ} \mathrm{C} / \mathrm{min}$ heating rate. Derivative thermogravimetric (DTG) curves were obtained afterward by temperature derivation of the TGA data.

The porosity of the ceramic water filters was measured via water absorption. In fact, the measurements were performed using fired samples with dimensions of $30 \times 30 \times 5 \mathrm{~mm}^{3}$. The fired samples were introduced in a desiccator and subjected to a vacuum pressure of $30 \mathrm{kPa}(4 \mathrm{~h})$. This was followed by partial immersion $(2 \mathrm{~h})$ and full immersion $(24 \mathrm{~h})$ in water under the same vacuum pressure. The atmospheric pressure was then restored in the desiccator where the samples remained immersed for an additional $24 \mathrm{~h}$. Following this operation, the mass of the samples was measured under water (i.e., hydrostatic weighing), under air, and after drying at $105^{\circ} \mathrm{C}$ for $24 \mathrm{~h}$ to estimate the volume fraction of pores. The estimates were obtained from Eq. (1), where $m_{h}=$ hydrostatic mass, $m_{w}=$ wet mass, and $m_{d}=$ dry mass:

$$
\varepsilon=\frac{m_{w}-m_{d}}{m_{w}-m_{h}}
$$

The micrometer-scale pores of the ceramic water filters were observed via scanning electron microscopy (SEM) using a Quanta 200 FEG apparatus (FEI, Hillsboro, Oregon). The samples were embedded in a solidifying epoxy resin and polished before imaging. The imaging was performed under backscattered electron (BSE) imaging conditions using an acceleration voltage of $10 \mathrm{kV}$ and a working distance of $10 \mathrm{~mm}$.

The distribution of the nanoscale pores was determined on the basis of gas adsorption theory. Analyses were performed in an Autosorb-1-C system (Quantachrome, Boynton Beach, Florida) using nitrogen as the adsorptive and cylindrical samples with a mass of $1 \mathrm{~g}$. The samples were degassed via heating under vacuum at $180^{\circ} \mathrm{C}$ for $12 \mathrm{~h}$. Following the gas adsorption analyses, the pore size distributions were calculated using the Barrett-Joyner-Halenda (BJH) method (Barrett et al. 1951). The Brunauer-Emmett-Teller (BET) method was also used to estimate the specific surface areas of the samples (Brunauer et al. 1938).
The volume of water discharged from the ceramic water filters was determined using the density (i.e., $1 \mathrm{~g} \cdot \mathrm{cm}^{-3}$ ) and the discharged mass of water. Typically, the discharged mass of water was obtained by measuring the mass of water collected in a bucket placed under the ceramic water filters. The measurements were carried out using a PGL 20001 balance (Adam Equipment, Oxford, Connecticut). The data were also collected as a function of time using Adam Equipment DU software. Following the experiments, the flow rates of the ceramic water filters were calculated by dividing the discharged volume of water by the corresponding time of discharge.

The permeability of the ceramic water filters, $k$, was calculated from Darcy's law. The calculations were made via Eq. (2) (Bear 1972), where $Q=$ flow rate of the ceramic water filters, $L=$ length over which the water flows (i.e., thickness of the base), $A=$ crosssectional area of the base, $\mu=$ viscosity of water, $\rho=$ density of water, $g=$ gravitational constant, and $\mathrm{h}=$ height of water above the base of the ceramic water filters:

$$
k=\frac{Q \mu L}{A \rho g h}
$$

The flow rate of the ceramic water filters was obtained from the discharge experiments. The thickness of the base, the crosssectional area of the base, and the height of water above the base of the ceramic water filters were measured using a caliper. They were equal to 15,180 , and $250 \mathrm{~mm}$, respectively, for the different ceramic water filters. The viscosity and density of water were treated as being equal to $1 \mathrm{mPa} \cdot \mathrm{s}$ and $1 \mathrm{~g} \cdot \mathrm{cm}^{-3}$.

\section{Determination of Removal Efficiency}

The efficiency of the ceramic water filters at removing some contaminants from water was tested for bacteria, chemicals, and viruses, which are the main sources of contamination for drinking water (see "Introduction"). This was carried out using E. coli (bacteria), fluoride (chemical), and MS2 (virus) as model contaminants (suspensions/solutions). The concentration of the aqueous suspensions/solutions was measured prior to filtration and after filtration with the maximum amount of water (i.e., approximately $10 \mathrm{~L}$ ) in the ceramic water filters. The efficiency was estimated using Eq. (3), where LRV $=\log$ reduction value, $C_{P F}=$ concentration prior to filtration, and $C_{A F}=$ concentration after filtration. The results of the LRV correspond to the average value of 20 replicates or more:

$$
\mathrm{LRV}=-\log _{10}\left(C_{A F} / C_{P F}\right)
$$

E. coli (C-3000 strain, ATCC 15597) was grown in an Escherichia medium (ATCC Medium 271) at $37^{\circ} \mathrm{C}$ for $24 \mathrm{~h}$. The growth was carried out under shaking (200 rpm) using a G25 incubator shaker (New Brunswick Scientific, Enfield, Connecticut). E. coli suspensions were prepared by mixing $10 \mathrm{~mL}$ of the stationary phase culture into $10 \mathrm{~L}$ deionized water. The suspensions were poured in the ceramic water filters with a number of viable cells (colony-forming units, $\mathrm{cfu} \cdot \mathrm{mL}^{-1}$ ) of $10^{6.26}$. This was regarded as sufficient to collect a minimum of $10^{1}$ viable cells after the filtration process. The number of viable cells was measured using $E$. coli count plates (Petrifilm, 3M, St. Paul, Minnesota), carried out following incubation of the count plates at $37^{\circ} \mathrm{C}$ for $24 \mathrm{~h}$.

The aqueous solutions of fluoride $(10 \mathrm{~L})$ were prepared by dissolution of sodium fluoride (Sigma-Aldrich, St. Louis) in deionized water. The concentration of the aqueous solutions was equal to $1,000 \mathrm{ppm}$. This was regarded as the minimum concentration to be above the detection limit of the instrument (i.e., $1 \mathrm{ppb}$ ) after 
filtration of the aqueous solutions. The measurements were performed using ion chromatography (ICS-2100, Dionex, Sunnyvale, California).

MS2 bacteriophage (ATCC 15597B1) was grown via broth propagation. The propagation was carried out using a growing culture (6 h old) of E. coli (C-3000 strain, ATCC 15597). After propagation, the bacteriophages were purified by centrifugation and mixed into deionized water $(10 \mathrm{~L})$. The number of viable cells (plate-forming units, $\mathrm{pfu} \cdot \mathrm{mL}^{-1}$ ) in the resulting suspensions of MS2 was equal to $10^{5.28}$. This was sufficient to collect a minimum of $10^{1}$ viable cells after filtration of the aqueous solutions. The enumeration was carried out using the double agar overlay plaque assay. Further details on this technique can be found in the literature (Kropinski et al. 2009).

\section{Determination of Mechanical Properties}

The mechanical properties of the ceramic water filters were measured via three-point bending tests. The measurements were performed in an Instron 8548 microtester (Norwood, Massachusetts) with a $500 \mathrm{~N}$ load cell and a $50 \mathrm{~mm}$ load span. The specimens with dimensions of $60 \times 10 \times 5 \mathrm{~mm}^{3}$ were prepared from the top section of the ceramic water filters (considering bottom, middle, and top sections on the circumference). They were all cut in the vertical direction using a wet-tile saw. The three-point bending tests were conducted with a constant displacement rate of $1 \mathrm{~mm} / \mathrm{min}$ until onset of fracture. The mechanical strength, $\sigma$, was estimated from Eq. (4), where $F_{\text {Max }}=$ maximum force, $L=$ loading span, $B=$ breadth, and $H=$ height of the specimens (ASTM 2017):

$$
\sigma=\frac{3 F_{\mathrm{Max}} L}{2 B H^{2}}
$$

The fracture toughness of the ceramic water filters was determined using single edge notch bend (SENB) specimens. The SENB specimens with dimensions of $60 \times 10 \times 5 \mathrm{~mm}^{3}$ and notches of $2 \mathrm{~mm}(0.40-0.45$ length-to-width ratio) were tested in the same Instron 8548 microtester that was used for the measurements of strength. They were loaded at the same displacement rate of $1 \mathrm{~mm} / \mathrm{min}$ until pop-in was observed at the notch:

$$
K_{I c}=f(a / W) \times \sigma_{f} \times \sqrt{\pi a}
$$

The stress intensity factor $\left(K_{I c}\right)$ was calculated from Eq. (5), where $\sigma_{f}=$ stress at the peak load, $a=$ crack length, and $f(a / W)=$ a compliance function (ASTM 2012).

\section{Results and Discussion}

\section{Structure of Ceramic Water Filters}

The thermal behavior of the ceramic water filters (i.e., derivative of the mass loss) is presented in Fig. 2. The results show that the filters are subjected to several reactions during the firing process, including to dehydration with a water release at temperatures between $30^{\circ} \mathrm{C}$ and $100^{\circ} \mathrm{C}$. Between $250^{\circ} \mathrm{C}$ and $450^{\circ} \mathrm{C}$, the sawdust is also subjected to combustion in the filters. This results in a transformation of the sawdust into water and carbon dioxide (Yi et al. 2013). However, it can be observed that the filters are highly stable up to $950^{\circ} \mathrm{C}$. The incorporation of hydroxyapatite and alumina does not modify the stability of the filters. The filters incorporating hydroxyapatite and alumina conserve the same thermal behavior as the conventional ones. This means that hydroxyapatite and alumina are not subjected to any decomposition in the clay matrix.

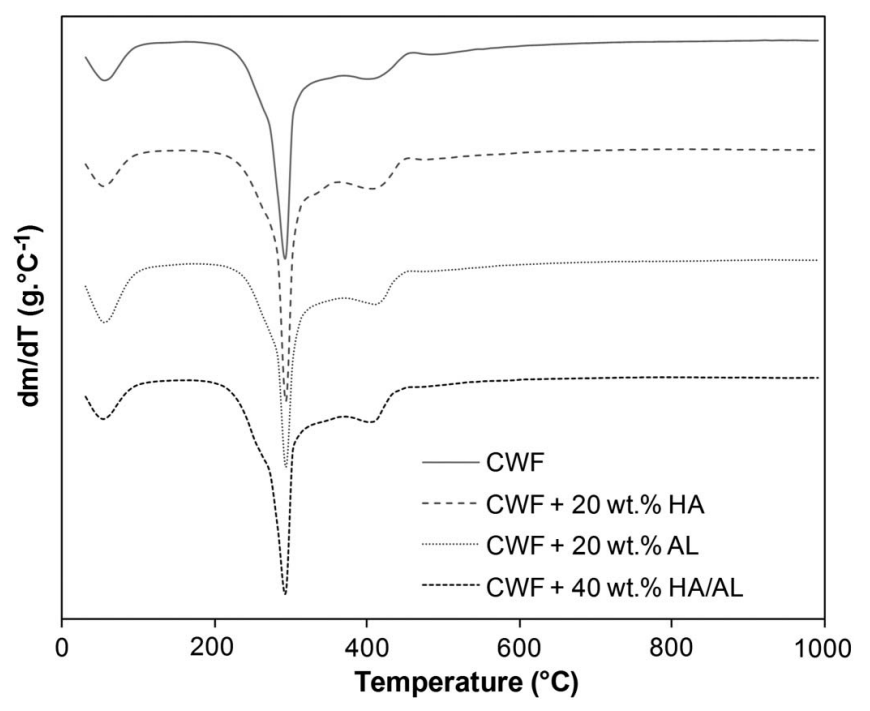

Fig. 2. Derivative thermogravimetric (DTG) curves of ceramic water filters without additives (CWF), ceramic water filter with $20 \mathrm{wt} . \%$ incorporation of hydroxyapatite (CWF + $20 \mathrm{wt} . \% \mathrm{HA})$, a $20 \mathrm{wt} \%$ incorporation of alumina $(\mathrm{CWF}+20 \mathrm{wt} . \% \mathrm{AL})$, and a $40 \mathrm{wt} . \%$ incorporation of hydroxyapatite and alumina (CWF + $40 \mathrm{wt}$. $\% \mathrm{HA} / \mathrm{AL})$ after firing of ceramic water filters at $950^{\circ} \mathrm{C}$ in air atmosphere. Data were obtained from TGA analysis.

The SEM micrographs obtained after firing of the ceramic water filters at a temperature of $950^{\circ} \mathrm{C}$ are presented in Fig. 3 . The images show that the filters are highly porous. Some of the pores are related to the processing of the filters (i.e., pressing and drying). These pores are relatively small in the clay matrix and have dimensions of approximately $10 \mu \mathrm{m}$. However, some other large-dimension pores, approximately $500 \mu \mathrm{m}$, can also be observed in the SEM micrographs. The dimensions of these pores are equivalent to the dimensions of the sawdust particles. In fact, they correspond to the voids released by combustion of the sawdust in the clay matrix during the firing process. These pores, generated between $250^{\circ} \mathrm{C}$ and $450^{\circ} \mathrm{C}$, are conserved as having the same dimensions up to $950^{\circ} \mathrm{C}$. The addition of hydroxyapatite does not modify the structure of the filters. The filters incorporating hydroxyapatite conserve a porous structure with 10 and $500 \mu \mathrm{m}$ pores after firing at a temperature of $950^{\circ} \mathrm{C}$. In contrast to the hydroxyapatite, alumina particles are clearly visible in the SEM micrographs. The $100 \mu \mathrm{m}$ particles of alumina are embedded in the matrix without any apparent interaction with the clay. It can be noted that alumina particles are relatively small compared to the micrometer-scale pores resulting from the combustion of the sawdust particles.

The pore size distributions obtained after firing of the ceramic water filters at $950^{\circ} \mathrm{C}$ are presented in Fig. 4. They show that the ceramic water filters without additives do not contain a significant fraction of pores at the nanoscale. In fact, the porosity is limited to the microscopic pores that result from the processing of the ceramic water filters (i.e., pressing and drying) and the combustion of the sawdust. The incorporation of hydroxyapatite does not modify the nanostructure of the filters. The ceramic water filters incorporating hydroxyapatite have the same structure as conventional filters at both the nano- and micrometer scales. In fact, the only difference between the ceramic water filters is the elemental composition of the solid fraction. The ceramic water filters incorporating alumina have an important fraction of pores at the nanoscale. These pores, 


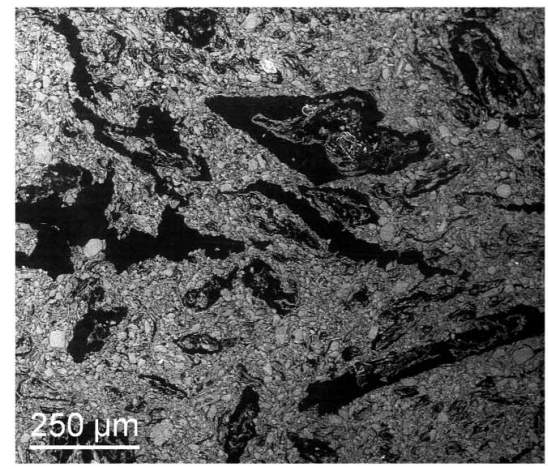

(a)

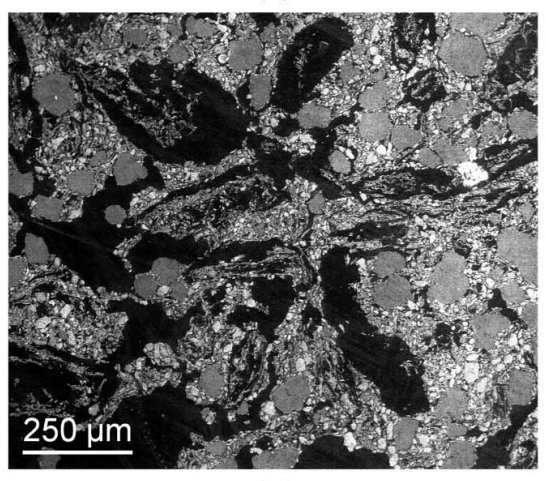

(c)

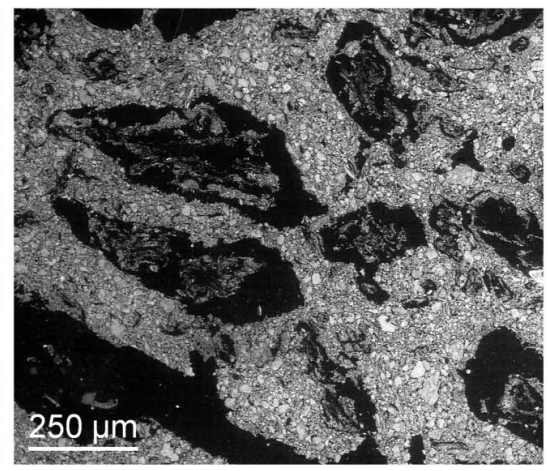

(b)

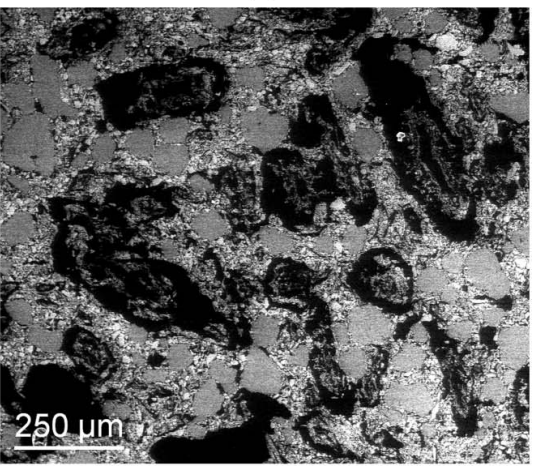

(d)

Fig. 3. SEM micrographs of (a) CWF; (b) CWF + $20 \mathrm{wt} . \% \mathrm{HA}$; (c) CWF + $20 \mathrm{wt} . \% \mathrm{AL}$; and (d) CWF + $40 \mathrm{wt} . \% \mathrm{HA} / \mathrm{AL}$ after firing of ceramic water filters at $950^{\circ} \mathrm{C}$ in air atmosphere.

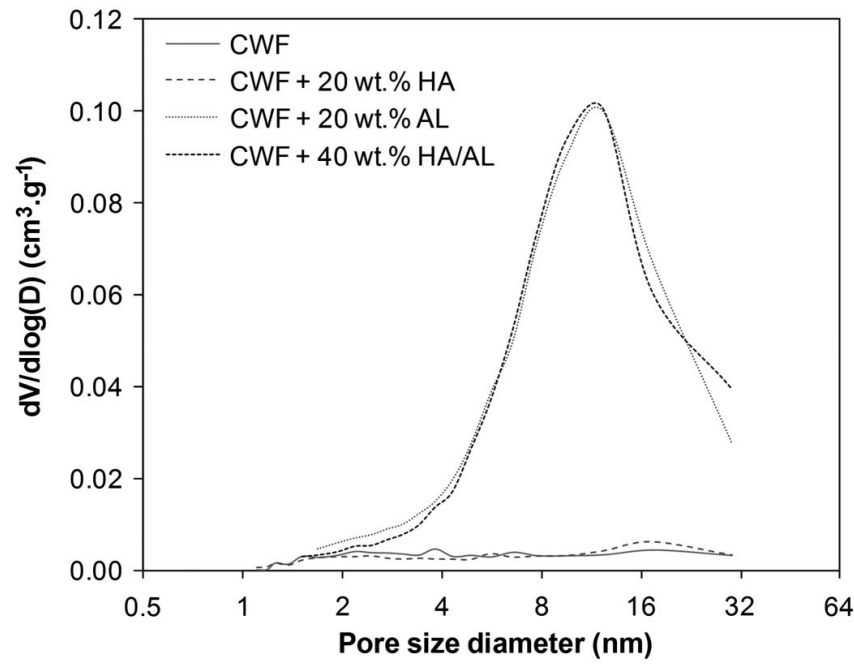

Fig. 4. Pore size distribution of CWF, CWF + $20 \mathrm{wt} . \% \mathrm{HA}, \mathrm{CWF}+$ 20 wt. $\%$ AL, and CWF + 40 wt. $\%$ HA/AL after firing of ceramic water filters at $950^{\circ} \mathrm{C}$ in air atmosphere. Data were obtained using nitrogen adsorption analysis with BJH method.

with an average diameter of $10 \mathrm{~nm}$, correspond to the pores of the alumina. Typically, they occur in addition to the microscopic pores from the clay matrix. This means that ceramic water filters incorporating alumina contain a wide range of pores with sizes varying from $10 \mathrm{~nm}$ at the nanoscale to $500 \mu \mathrm{m}$ at the microscopic scale.

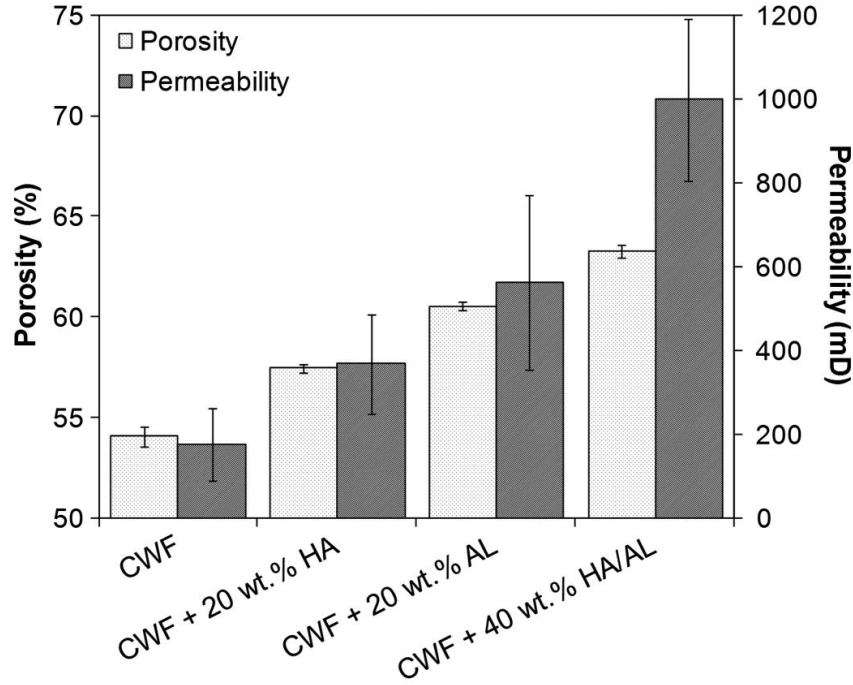

Fig. 5. Percentage of porosity and permeability of CWF, CWF $+20 \mathrm{wt}$. $\% \mathrm{HA}, \mathrm{CWF}+20 \mathrm{wt} . \% \mathrm{AL}$, and $\mathrm{CWF}+40 \mathrm{wt} . \% \mathrm{HA} / \mathrm{AL}$ after firing of ceramic water filters at $950^{\circ} \mathrm{C}$ in an air atmosphere. Data were obtained using Darcy's law and water absorption analysis.

The dependence of the permeability on the percentage of porosity after firing of the ceramic water filters at $950^{\circ} \mathrm{C}$ is presented in Fig. 5. The results show that ceramic water filters without additives have a porosity of 54 vol. $\%$. They also indicate that their permeability is equal to $176 \mathrm{mD}$. The incorporation of hydroxyapatite and alumina increases the porosity of the ceramic 


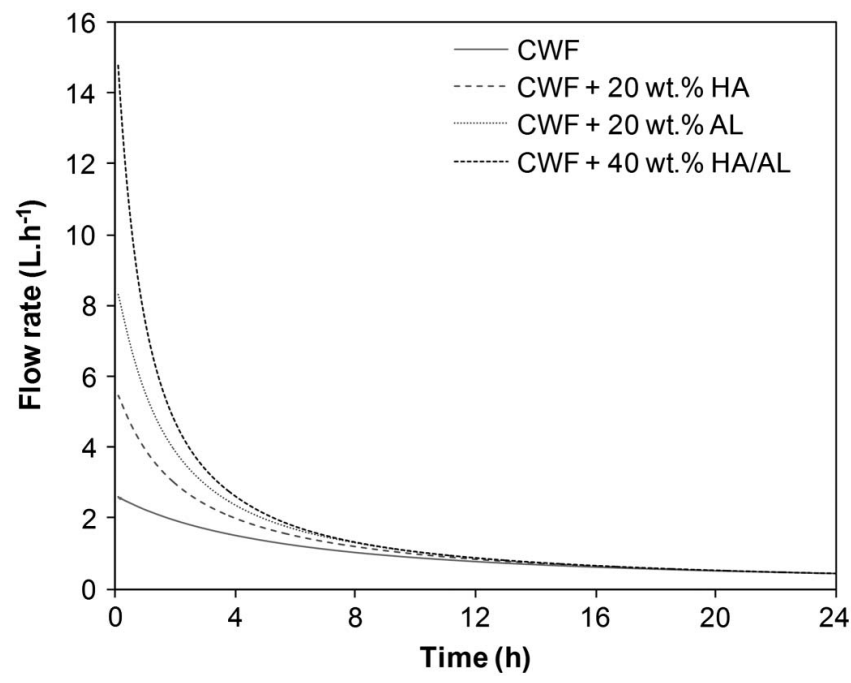

Fig. 6. Flow rate of CWF, CWF + 20 wt. $\% \mathrm{HA}, \mathrm{CWF}+20$ wt. $\%$ $\mathrm{AL}$, and $\mathrm{CWF}+40$ wt. $\% \mathrm{HA} / \mathrm{AL}$ after firing of ceramic water filters at $950^{\circ} \mathrm{C}$ in an air atmosphere. Data were obtained using water discharge.

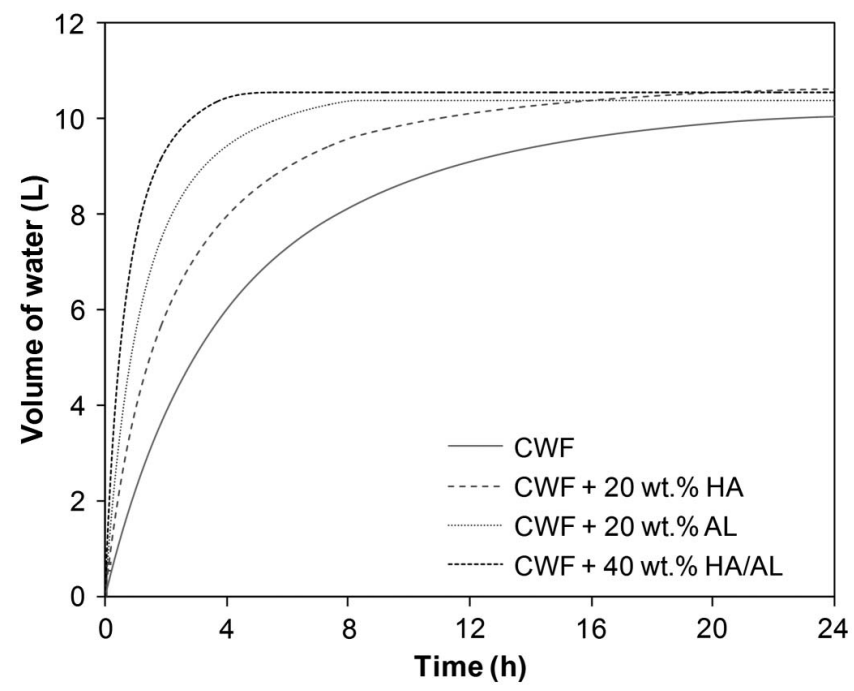

Fig. 7. Discharge of CWF, CWF + 20 wt. $\% \mathrm{HA}, \mathrm{CWF}+20 \mathrm{wt} . \%$ $\mathrm{AL}$, and $\mathrm{CWF}+40 \mathrm{wt} . \% \mathrm{HA} / \mathrm{AL}$ after firing of ceramic water filters at $950^{\circ} \mathrm{C}$ in air atmosphere. Data were obtained using continuous mass acquisition. water filters. The porosity of the filters increases to $63 \mathrm{vol} . \%$ for a 40 wt. $\%$ addition of hydroxyapatite and alumina. This increase in the porosity results in an important increase of the permeability. In fact, the permeability of the ceramic water filters incorporating hydroxyapatite and alumina increases to $998 \mathrm{mD}$. The results suggest that the permeability is directly proportional to the porosity (which is proportional to the amount of additives) up to a certain percentage of porosity (i.e., approximately $62 \%$ ) for which the ceramic water filters become much more permeable.

\section{Hydraulic Properties of Ceramic Water Filters}

The flow rates of the ceramic water filters obtained after firing at $950^{\circ} \mathrm{C}$ are presented in Fig. 6. The results show that the highest flow rates are reached at the beginning (i.e., at $0 \mathrm{~h}$ ). This corresponds to the moment at which the filters contain the highest volumes of water (i.e., $10 \mathrm{~L}$ ). After some of the water is discharged from the filters, a lower pressure is applied at their base, resulting in a decrease of the flow rates with time. It can be observed that the filters incorporating hydroxyapatite and alumina have relatively higher flow rates than the conventional filters. Typically, the incorporation of hydroxyapatite and alumina increases the flow rates of the filters from 2.6 to $14.8 \mathrm{~L} \cdot \mathrm{h}^{-1}$. This is due to the fact that the permeability of the filters incorporating hydroxyapatite and alumina is much higher (i.e., $998 \mathrm{mD}$ ) than that of the conventional filters (i.e., $176 \mathrm{mD}$ ).

The volume of water discharged from the ceramic water filters as a function of time is presented in Fig. 7. The results show that the water discharge is relatively fast at the beginning and tends to slow down with time. In fact, the results indicate that the water discharge is controlled by the flow rates of the filters. The incorporation of hydroxyapatite and alumina into the filters results in a significant increase in the flow rates (Fig. 5). Hence, the ceramic water filters incorporating hydroxyapatite and alumina have a shorter time of discharge than the conventional ones. The discharge time of the ceramic water filters decreases from 24 to $4 \mathrm{~h}$ for a $40 \mathrm{wt}$. $\%$ incorporation of hydroxyapatite and alumina. This means that $10 \mathrm{~L}$ of contaminated water could be purified every $4 \mathrm{~h}$ using such ceramic water filters.

The physical properties of the ceramic water filters obtained after firing at a temperature of $950^{\circ} \mathrm{C}$ are given in Table 4. The results show that the filters incorporating hydroxyapatite and alumina have a significant percentage of porosity (i.e., $63 \mathrm{vol} \%$ ). The porosity of the filters is composed of a wide range of pores with sizes varying from $10 \mathrm{~nm}$ to $500 \mu \mathrm{m}$. The nanopores associated with the alumina provide a high specific surface area (i.e., $21.0 \mathrm{~m}^{2} \cdot \mathrm{g}^{-1}$ ) to the ceramic water filters. On the other hand, the microscopic pores resulting from the processing of the filters (i.e., pressing and drying) and the combustion of the sawdust

Table 4. Porosity, permeability, flow rate, and specific surface area of the ceramic water filters after firing at $950^{\circ} \mathrm{C}$ in an air atmosphere

\begin{tabular}{lcccr}
\hline Sample & $\begin{array}{c}\text { Porosity } \\
(\text { vol.\% })\end{array}$ & $\begin{array}{c}\text { Permeability } \\
(\mathrm{mD})\end{array}$ & $\begin{array}{c}\text { Flow rate } \\
\left(\mathrm{L} \cdot \mathrm{h}^{-1}\right)\end{array}$ & $\begin{array}{r}\text { Specific surface } \\
\text { area }\left(\mathrm{m}^{2} \cdot \mathrm{g}^{-1}\right)\end{array}$ \\
\hline CWF & $54.0 \pm 0.5$ & $176 \pm 86$ & $2.6 \pm 0.6$ & $3.7 \pm 0.6$ \\
CWF + 20 wt.\% HA & $57.4 \pm 0.2$ & $367 \pm 120$ & $5.4 \pm 0.9$ & $3.8 \pm 0.7$ \\
CWF + 20 wt.\% AL & $60.5 \pm 0.2$ & $561 \pm 208$ & $8.3 \pm 1.5$ & $20.9 \pm 1.0$ \\
CWF + 40 wt.\% HA/AL & $63.3 \pm 0.3$ & $998 \pm 193$ & $14.8 \pm 1.4$ & $21.0 \pm 0.9$ \\
\hline
\end{tabular}

Note: Data were obtained using water absorption analysis (porosity), Darcy's law (permeability), water discharge (flow rate), and nitrogen adsorption analysis with the BET method (specific surface area); error ranges of porosity, permeability, and flow rates were determined from standard deviation of at least 20 replicates. 


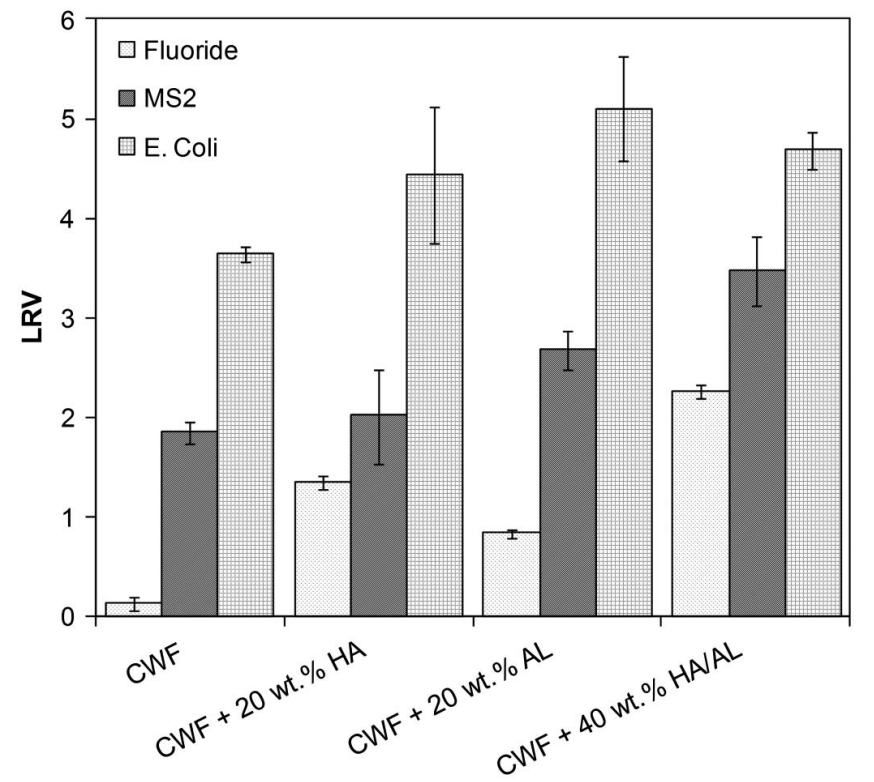

Fig. 8. Log reduction values (LRV) for fluoride, MS2, and E. coli of CWF, CWF + 20 wt. \% HA, CWF + 20 wt. \% AL, and CWF + 40 wt. \% HA/AL. Data were obtained using ion chromatography (fluoride), double agar overlay plaque assay (MS2), and count plate enumeration (E. coli).

particles increase the filters' permeability (i.e., $998 \mathrm{mD}$ ) and the flow rate (i.e., $14.8 \mathrm{~L} \cdot \mathrm{h}^{-1}$ ), which improves the discharge (i.e., $10 \mathrm{~L}$ water in $4 \mathrm{~h}$ ).

\section{Removal Efficiency of Ceramic Water Filters}

The log reduction values (LRVs) of the ceramic water filters are presented in Fig. 8. The results show that the filters without additives have LRVs of 0.13 for fluoride (i.e., removal efficiency of $25.87 \%$ ), 1.85 for MS2 (i.e., removal efficiency of $98.59 \%$ ), and 3.64 for $E$. coli (i.e., removal efficiency of $99.98 \%$ ). These values are comparable to those from the literature (Lantagne 2001; van Halem 2006). They confirm that the efficiency of such filters is limited to the removal of bacterial contaminants. Typically, the bacterial contaminants are removed from water by trapping in the pores. The incorporation of hydroxyapatite into the ceramic water filters increases the percentage of porosity. Hence, the filters incorporating hydroxyapatite have a greater efficiency than conventional filters in the removal of $E$. coli (i.e., LRV of 4.43 with removal efficiency of $99.996 \%$ ). The ceramic water filters with a $20 \mathrm{wt} . \%$ incorporation of hydroxyapatite have a greater efficiency in the removal of fluoride (i.e., LRV of 1.34 with removal efficiency of $95.43 \%$ ). This increase in the removal of fluoride is associated with a complementary mechanism of capture. In fact, some chemical contaminants are removed from water by substitution for calcium ions, phosphate groups, or hydroxyl groups from the hydroxyapatite that was conserved in the clay matrix (de Leeuw 2002).

It can be observed that the conservation of alumina also increases the efficiency of the ceramic water filters at removing viral contaminants from drinking water. This is due to the fact that the conservation of alumina results in a significant increase of the specific surface area (Table 4). Hence, the viral contaminants can be removed by the filters incorporating alumina via a surface-based mechanism of adsorption (especially within the nanopores of

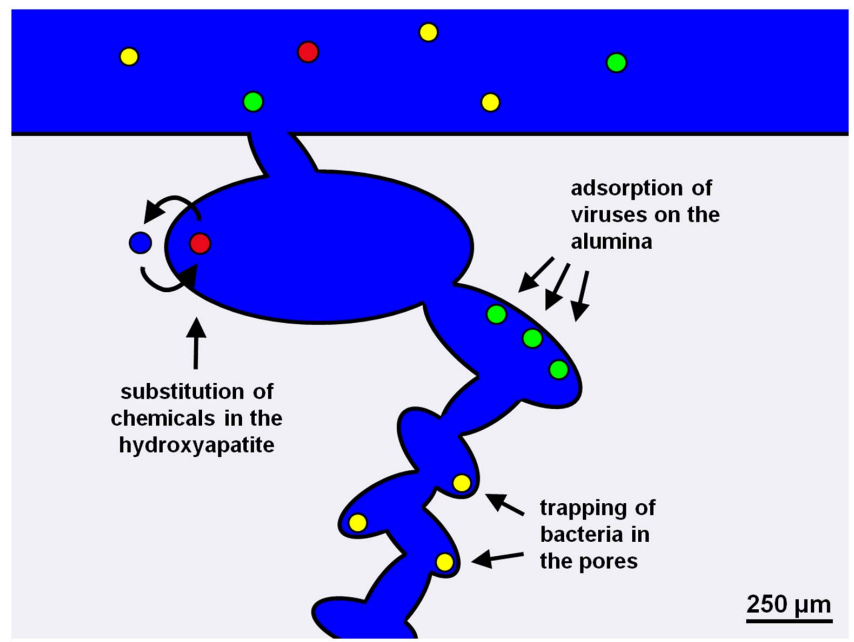

Fig. 9. Schematic of capture mechanisms (i.e., trapping, substitution, and adsorption).

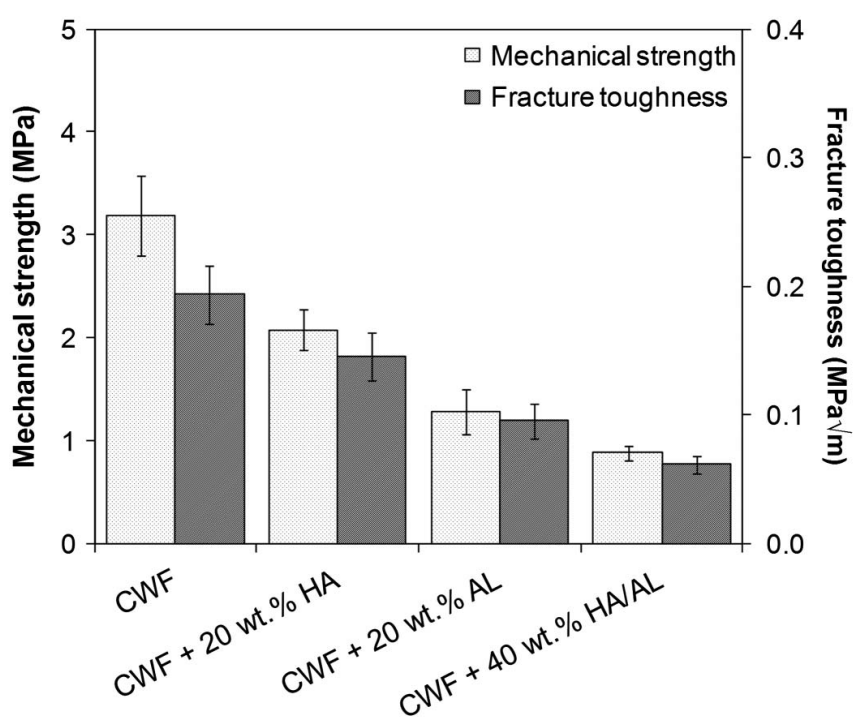

Fig. 10. Mechanical strength and fracture toughness of CWF, CWF + 20 wt. $\%$ HA, CWF + 20 wt. $\%$ AL, and CWF + 40 wt. \% HA/AL after firing of ceramic water filters at $950^{\circ} \mathrm{C}$ in air atmosphere. Data were obtained using a three-point bend testing configuration.

alumina). The capture mechanisms of the filters (i.e., trapping, substitution, and adsorption) are related to different parameters (i.e., porosity, hydroxyapatite, and alumina). This means that the ceramic water filters incorporating hydroxyapatite and alumina combine the different capture mechanisms, as shown in Fig. 9. They are efficient at removing bacterial, chemical, and viral contaminants from drinking water. The LRVs of the ceramic water filters incorporating hydroxyapatite and alumina are equal to 2.26 for fluoride (i.e., removal efficiency of $99.45 \%$ ), 3.47 for MS2 (i.e., removal efficiency of $99.97 \%$ ), and 4.69 for $E$. coli (i.e., removal efficiency of $99.998 \%$ ).

\section{Mechanical Properties of Ceramic Water Filters}

The mechanical properties of the ceramic water filters obtained after firing at $950^{\circ} \mathrm{C}$ are presented in Fig. 10. The results show that 
the filters without additives have a mechanical strength of $3.18 \mathrm{MPa}$ and a fracture toughness of $0.19 \mathrm{MPa} \cdot \mathrm{m}^{1 / 2}$. It can also be observed that the mechanical strength and the fracture toughness of the filters decrease with the incorporation of additives. This is due to the fact that the additives are embedded in the matrix without any interaction with the clay (Fig. 3). Therefore, the additives appear as a source of fracture for the filters. The incorporation of hydroxyapatite decreases the mechanical strength and the fracture toughness to $2.08 \mathrm{MPa}$ and $0.15 \mathrm{MPa} \cdot \mathrm{m}^{1 / 2}$, respectively. The alumina has large particles (i.e., $100 \mu \mathrm{m}$ ) in comparison with the hydroxyapatite (i.e., $5 \mu \mathrm{m}$ ). Hence, the incorporation of alumina results in a greater decrease of the mechanical properties than the incorporation of hydroxyapatite. The filters incorporating alumina have a mechanical strength of $1.28 \mathrm{MPa}$ and a fracture toughness of $0.10 \mathrm{MPa} \cdot \mathrm{m}^{1 / 2}$. As a result, the mechanical strength and fracture toughness of the filters incorporating hydroxyapatite and alumina are equal to $0.88 \mathrm{MPa}$ and $0.06 \mathrm{MPa} \cdot \mathrm{m}^{1 / 2}$, respectively.

\section{Implications}

The implications of this research are significant for the development of household water treatment. Household water treatment technologies such as ceramic water filters are widely used due to their ease of production and operation and their high efficiency at removing bacterial contaminants from drinking water. However, water may still be unsafe to drink after filtration due to the presence of chemical and viral contaminants.

This work shows that ceramic water filters can be efficient at the removal of bacterial, chemical, and viral contaminants from drinking water. The different types of contaminants are removed from drinking water by doping the filters with hydroxyapatite and alumina, resulting in a combination of capture mechanisms (trapping, substitution, adsorption). In this study, the efficiency of doped ceramic water filters was equal to $99.45 \%$ in the removal of chemical contaminants (i.e., LRV of 2.26), 99.97\% in the removal of viral contaminants (i.e., LRV of 3.47), and $99.998 \%$ in the removal of bacterial contaminants (i.e., LRV of 4.69). Furthermore, doping with hydroxyapatite and alumina increased the flow rates of the filters. In $4 \mathrm{~h}$, doped ceramic water filters discharged up to $10 \mathrm{~L}$ of clean water. This means that each filter could purify up to $60 \mathrm{~L}$ water per day at a relatively limited cost (extra cost of $\$ 1.10$ per filter for real-life production).

\section{Conclusions}

In this study, a combination of capture mechanisms in ceramic water filters (doped with hydroxyapatite and alumina) was considered for the removal of bacterial, chemical, and viral contaminants from drinking water. Salient conclusions arising from this study are as follows:

1. Hydroxyapatite and alumina were conserved during the firing process of the ceramic water filters. They remained in the clay matrix with their initial composition/properties at temperatures up to $950^{\circ} \mathrm{C}$. In this way, the doped filters had a wide range of pores with sizes of $10 \mathrm{~nm}$ at the nanoscale to $500 \mu \mathrm{m}$ at the microscopic scale.

2. The nanopores associated with the doping of the ceramic water filters increased the specific surface area. On the other hand, the microscopic pores associated with the processing of the filters and the combustion of the sawdust increased the permeability and flow rate, resulting in a reduction in discharge time (10 L in $4 \mathrm{~h}$ ).

3. Bacterial, chemical, and viral contaminants were removed from drinking water by trapping in pores, substitution in the hydroxyapatite, and adsorption on the surface of alumina, respectively. Hence, the ceramic water filters incorporating hydroxyapatite and alumina combined different capture mechanisms.

4. Ceramic water filters incorporating hydroxyapatite and alumina had efficiencies of $99.45 \%$ in the removal of chemical contaminants (i.e., LRV of 2.26), 99.97\% in the removal of viral contaminants (i.e., LRV of 3.47), and $99.998 \%$ in the removal of bacterial contaminants (i.e., LRV of 4.69).

\section{Acknowledgments}

The authors acknowledge the CARNOT Mines Institute, the SOLSTICE Laboratory of Excellence, the RAPSODEE Research Center at Mines Albi, and the Department of Mechanical Engineering and the Department of Biology and Biotechnology at Worcester Polytechnic Institute for financial support. The authors are also grateful to the management and staff of the Department of Mechanical and Aerospace Engineering, the Department of Civil and Environmental Engineering, and the Andlinger Center for Energy and the Environment at Princeton University for their assistance with the research. Dr. Alex Maag is also thanked for performing the gas sorption analyses in this study.

\section{References}

ASTM. 2012. Standard test method for linear-elastic plane-strain fracture toughness $K_{I c}$ of metallic materials. ASTM E399. West Conshohocken, PA: ASTM.

ASTM. 2017. Standard test methods for flexural properties of unreinforced and reinforced plastics and electrical insulating materials. ASTM D790. West Conshohocken, PA: ASTM.

Barrett, E. P., L. G. Joyner, and P. Halenda. 1951. "The determination of pore volume and area distributions in porous substances. Part I: Computations from nitrogen isotherms." J. Am. Chem. Soc. 73 (1): 373-380. https://doi.org/10.1021/ja01145a126.

Bear, J. 1972. Dynamics of fluids in porous media. New York: Elsevier.

Bhatnagar, A., E. Kumar, and M. Sillanpää. 2011. "Fluoride removal from water by adsorption: A review." Chem. Eng. J. 171 (3): 811-840. https://doi.org/10.1016/j.cej.2011.05.028.

Bielefeldt, A. R., K. Kowalski, and R. S. Summers. 2009. "Bacterial treatment effectiveness of point-of-use ceramic water filters." Water Res. 43 (14): 3559-3565. https://doi.org/10.1016/j.watres.2009.04.047.

Brown, J., and M. D. Sobsey. 2009. "Ceramic media amended with metal oxide for the capture of viruses in drinking water." Environ. Technol. 30 (4): 379-391. https://doi.org/10.1080/09593330902753461.

Brown, J., and M. D. Sobsey. 2010. "Microbiological effectiveness of locally produced ceramic water filters for drinking water treatment in Cambodia." J. Water Health 8 (1): 1-10. https://doi.org/10.2166/wh 2009.007.

Brunauer, S., P. H. Emmett, and E. Teller. 1938. "Adsorption of gases in multimolecular layers.” J. Am. Chem. Soc. 60 (2): 309-319. https://doi .org/10.1021/ja01269a023.

De Leeuw, N. H. 2002. "Density functional theory calculations of local ordering of hydroxyl groups and fluoride ions in hydroxyapatite.' Phys. Chem. Chem. Phys. 4 (15): 3865-3871. https://doi.org/10.1039 /b203114k.

Hunter, P. R. 2009. "Household water treatment in developing countries: Comparing different interventions types using meta-regression." Environ. Sci. Technol. 43 (23): 8991-8997. https://doi.org/10.1021 /es9028217.

Järup, L. 2003. "Hazards of heavy metal contamination." Br. Med. Bull. 68 (1): 167-182. https://doi.org/10.1093/bmb/ldg032.

Kropinski, A. M., A. Mazzocco, T. E. Waddell, E. Lingohr, and R. P. Johnson. 2009. "Enumeration of bacteriophages by double agar overlay plaque assay." In Vol. 501 of Bacteriophages: Methods in molecular 
biology, edited by M. R. Clokie, and A. M. Kropinski, 69-76. New York: Humana Press.

Lantagne, D. S. 2001. Investigation of the potters for peace colloidal silverimpregnated ceramic filter: Intrinsic effectiveness and field performance in rural Nicaragua. Rep. for Alethia Environmental. Allston, MA: Alethia Environmental.

Meenakshi, A., and R. C. Maheshwari. 2006. "Fluoride in drinking water and its removal." J. Hazard. Mater. 137 (1): 456-463. https://doi.org/10 .1016/j.jhazmat.2006.02.024.

Michen, B., J. Fritsch, C. Aneziris, and T. Graule. 2013. "Improved virus removal in ceramic depth filters modified with MgO." Environ. Sci. Technol. 47 (3): 1526-1533. https://doi.org/10.1021/es303685a.

Michen, B., F. Meder, A. Rust, J. Fritsch, C. Aneziris, and T. Graule. 2012. "Virus removal in ceramic depth filters based on diatomaceous earth." Environ. Sci. Technol. 46 (2): 1170-1177. https://doi.org/10.1021 les2030565.

Nigay, P. M., A. Nzihou, C. E. White, and W. O. Soboyejo. 2018. "Removal mechanisms of contaminants in ceramic water filters." J. Environ. Eng. 144 (12): 04018128. https://doi.org/10.1061/(ASCE)EE.1943-7870 .0001471 .

Oyanedel-Craver, V. A., and J. A. Smith. 2008. "Sustainable colloidalsilver-impregnated ceramic filter for point-of-use water treatment." Environ. Sci. Technol. 42 (3): 927-933. https://doi.org/10.1021 les071268u.

Racaniello, V. R. 2006. "One hundred years of poliovirus pathogenesis." Virology 344 (1): 9-16. https://doi.org/10.1016/j.virol.2005.09.015.

Ramia, S. 1985. "Transmission of viral infections by the water route: Implications for developing countries." Rev. Infect. Dis. 7 (2): 180-188. https://doi.org/10.1093/clinids/7.2.180.

Sobsey, M. D., C. E. Stauber, L. M. Casanova, J. M. Brown, and M. A. Elliott. 2008. "Point of use household drinking water filtration: A practical, effective solution for providing sustained access to safe drinking water in the developing world." Environ. Sci. Technol. 42 (12): 4261-4267. https://doi.org/10.1021/es702746n.

Tsao, N. H., K. A. Malatesta, N. E. Anuku, and W. O. Soboyejo. 2016. "Virus filtration in porous iron (III) oxide doped ceramic water filters." Adv. Mater. Res. 1132: 284-294. https://doi.org/10.4028/www .scientific.net/AMR.1132.284.

van der Laan, H., D. van Halem, P. W. M. H. Smeets, A. I. A. Soppe, J. Kroesbergen, G. Wubbels, J. Nederstigt, I. Gensburger, and S. G. J. Heijman. 2014. "Bacteria and virus removal effectiveness of ceramic pot filters with different silver applications in a long term experiment." Water Res. 51 (Mar): 47-54. https://doi.org/10.1016/j.watres.2013.11 .010 .

Van Halem, D. 2006. "Ceramic silver impregnated pot filters for household drinking water treatment in developing countries." M.Sc. thesis, Dept. of Water Management, Delft Univ. of Technology.

WHO (World Health Organization). 2001. Water for health: Taking charge. Geneva: WHO.

Yakub, I., et al. 2013. "Porosity, flow, and filtration characteristics of frustum-shaped ceramic water filters." J. Environ. Eng. 139 (7): 986-994. https://doi.org/10.1061/(ASCE)EE.1943-7870.0000669.

Yakub, I., and W. O. Soboyejo. 2013. "Adsorption of fluoride from water using sintered clay-hydroxyapatite composites." J. Environ. Eng. 139 (7): 995-1003. https://doi.org/10.1061/(ASCE)EE.1943-7870.00 00692.

Yi, Q., F. Qi, G. Cheng, Y. Zhang, B. Xiao, Z. Hu, S. Liu, H. Cai, and S. Xu. 2013. "Thermogravimetric analysis of co-combustion of biomass and biochar." J. Therm. Anal. Calorim. 112 (3): 1475-1479. https://doi .org/10.1007/s10973-012-2744-1.

Younes, M., and H. Galal-Gorchev. 2000. "Pesticides in drinking water: A case study." Food Chem. Toxicol. 38 (1): S87-S90. https://doi.org/10 .1016/S0278-6915(99)00132-5. 